\title{
The Invisible Body-Balancing Economics: A Medium Approach
}

\author{
Masayuki Matsui \\ Department of Industrial Engineering and Management, Kanagawa University, Yokohama, Japan \\ Email: matsui@kanagawa-u.ac.jp
}

Received 15 January 2015; accepted 31 January 2015; published 3 February 2015

Copyright (C) 2015 by author and Scientific Research Publishing Inc.

This work is licensed under the Creative Commons Attribution International License (CC BY). http://creativecommons.org/licenses/by/4.0/

(c) (i) Open Access

\begin{abstract}
Our global world is under the variety of individual bodies on the division of work. This paper would consider the invisible body-balancing network and economics by a medium approach. This medium approach originated from the Newsboy problem, and would be attained by the invisible hand of market (demand) speed at Chameleon's criteria. First, our new treatment and condition to balancing are given. Next, a few trial cases are discussed and verified at the series type.
\end{abstract}

Keywords

Balancing, Medium Approach, Individual Body, Newsboy, Invisible Hand, SCM/GDP

\section{Introduction}

There are a variety of individual bodies on the division of work. This paper would consider the invisible bodybalancing network and economics by a medium approach. This medium approach originated from a Newsboy problem [1], and would be attained by the invisible hand of market (demand) speed.

The traditional balancing problem originates from Ford system, and is essential to the economy of mass production (economics) in the automobile industry [2]. This problem is dependent on the demand and supply speed (cycle time) in the market, and relates to the conveyor speed vs. efficiency (cycle time) in the assembly line.

The related domain is called the line balancing in Industrial Engineering (IE), and is based on the principle of system balancing in the assembly industry, including service types [3]. This solution method tends to pursue the mean inventory in the factory toward the lean inventory on the line speed in the demand-to-supply system (SCM).

In the Toyota system [4], the line speed is determined and balanced by the demand speed in the market, and Kanban system gives a solution method of the efficiency vs. muda (loss) in the demand and supply system of pull type. However, this solution tool is an improvement approach to lean inventory. 
We here consider the medium approach to the efficiency vs. muda (loss) problem in the stochastic system balancing, based on the medium inventory that originates from the Newsboy in Operations Research (OR). This paper would be prepared to apply this approach to the SCM/GDP system in the country-like region toward the near future.

\section{Body-Balancing System}

\subsection{Economics in Balancing Problem}

Modern society is being formed by the worldwide division of work as we move towards globalization. Since 1776, there is the problem of invisible hand by Smith [5], and this problem become more important at global economics. At the classics, the price is central (Smith), and the production quantity is at next considered as the newer actor (Keynes [6]). Recently, it is pointed out in Matsui [7] that the demand speed would be near to the invisible hand, because it would bring each maximal-profit (re-) balancing in the changeable market economy.

Generally, the body-centered network (SCM/GDP) might be able to be invisibly balanced and cooperated by the demand speed (God hand) and cloud computing [8]. However, there is the profit-balancing at series' types, otherwise may the cost-relative balancing at parallel types [9]. Thus, this God-like hand would be alive and the win-win would be attainable at not only SCM networks but also Smith's world only under equally partnership.

As an example, let us consider the two- or three-center model consisting of sales, assembly and fabrication centers [10]. The two main types of configuration are series and parallel systems. The SCM is a series type, and ERP (enterprise resource planning) is a parallel type. For a series class, the profit maximization is attainable under the demand speed given (shared), even if each heterogeneous agent (enterprises) pursues the self-goal in non-cooperation under indivisible environment.

Thus, each unit-optimization in profit gives the total optimization in sum under non-cooperation, and the point (balancing) occurs at near middle lead-time (reliability). This class is called the integral optimization, and might be governed by the Ellipse map and strategy in Matsui [11].

Our profit is corresponded to the marginal profit/value in Accounting/GDP, and it is similar to the medium criterion in [12]. In the classics, A. Smith presents the first concept on the invisible hand in 1759 [13], prior to 1776. This concept might be near to that of medium criterion in our balancing issues.

\subsection{Medium Balancing Approach}

The stochastic balancing problem is a class of the Conveyor-Serviced Production Station (CSPS) and its networks [14]. This study is called the station-centered approach to the power-conveyor system, and this station is here corresponded to the individual bodies (human, house, enterprise, etc.) in the society or country.

In the body balancing system, the definition of stochastic balancing is here as follows: A stabling phenomenon of transient, bottlenecked vs. balanced, state of the object system. The balanced solution by this stochastic balancing becomes quasi-optimal.

Recently, the medium approach to the body-balancing system is outlined to SCM type in Figure 1 [12]. In Figure 1, $d(>0)$ is the demand speed (cycle time), and also, $\beta_{i}$ and $M I_{i}$ are the medium criterion $(0<\beta<1)$, and moving-standard inventory in the individual body, $i \quad(i=1,2, \cdots, n)$, respectively.

The medium criterion, $\beta$, is controlled by $\bar{\beta}=\left(\beta_{3}-\beta_{1}\right) /\left(\beta_{2}+\beta_{3}\right)$, in which the parameters $\beta_{1}, \beta_{2}$ and $\beta_{3}$ are the cost coefficients (penalties) of inventory holdings, excess inventory and shortage inventory, respectively.

Now, the Newsvendor's condition [1] is the followings:

$$
F_{i}\left(M I_{i}\right)=\bar{\beta}_{i}, \quad i=1,2, \cdots, n
$$

where $F_{i}(\cdot)$ is the distribution function of the inventory in the in the individual body, $i$.

Then, the balancing goal is given by the following objective function:

$$
\alpha_{1} \bar{\beta}_{1}+\alpha_{2} \bar{\beta}_{2}+\cdots+\alpha_{n} \bar{\beta}_{n} \rightarrow \min _{d}\left\{\bar{\beta}_{i}\right\}
$$

where $a_{i}$ is the weight factor $\left(0<a_{i}\right), i=1,2, \cdots, n$. 


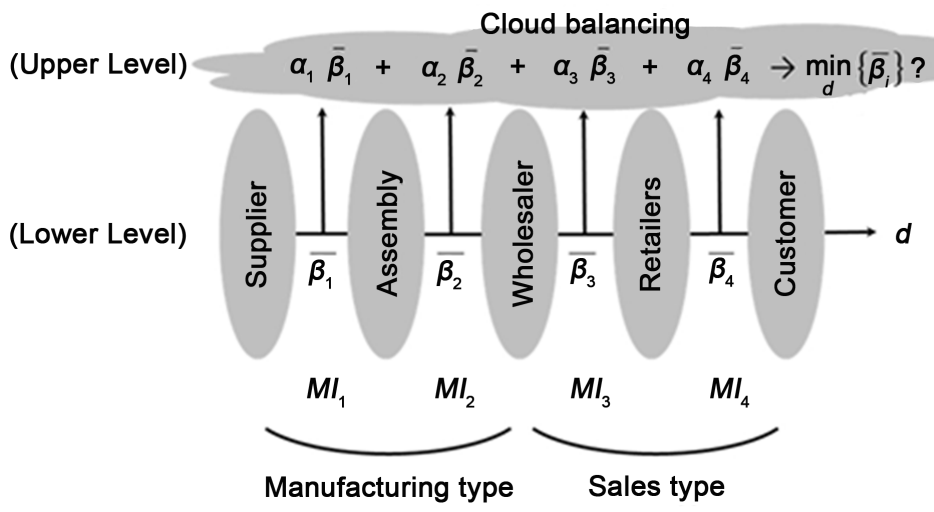

Figure 1. A body-balancing system of a supply chain (economics) in [7].

An optimal condition (balancing) is assumed from the classical inequality and Matsui's equation $(W=Z L)$ [12] as follows:

$$
\text { Hypothesis : } \alpha_{1} \bar{\beta}_{1}=\alpha_{2} \bar{\beta}_{2}=\cdots=\alpha_{n} \bar{\beta}_{n}=(W=Z L)
$$

In (3), $Z$ and $L$ correspond to $a_{i}$ and $\bar{\beta}_{i}$, respectively, and $W$ means a balancing value at the equilibrium.

\section{Two Balancing Principles}

\section{1. $d$-Balancing Principle}

Two principles on the medium balancing are here presented and considered. At first, the $d$-balancing problem (2) is seen on the upper level of 2-level scheme in Figure 1. This main problem is easily decomposed of the dual problem:

$$
F_{i}\left(I_{i}\right)=\bar{\beta}_{i}, \quad i=1,2, \cdots, n
$$

in the respective body of entity $i$. Matsui's point, $\bar{\beta}_{i}$, is based on the so-called Chameleon's criteria [12].

Now, the following condition is considered under the demand speed (cycle time), $d \quad(0<d<1)$, and the exponential service with the mean, $m_{i}$ (supply speed). That is,

$$
G_{i}(d)=1-\exp \left(-d / m_{i}\right)=\bar{\beta}_{i}, \quad i=1,2, \cdots, n
$$

and the demand speed, $d$, is as follows:

$$
d=-m_{i} \ln \left(1-\bar{\beta}_{i}\right)
$$

On $d$-balancing, the following relation is obtained from (6):

$$
m_{i} \ln \left(1-\bar{\beta}_{i}\right)=m_{j} \ln \left(1-\bar{\beta}_{j}\right), \quad i \neq j
$$

Especially, for Poisson service, the optimal condition is

$$
F_{i}\left(I_{i}\right)=\sum_{i=1}^{I_{i}} P\left(d ; m_{i}\right)=1-\bar{\beta}_{i}, \quad i=1,2, \cdots, n
$$

where $P(\cdot)$ is Poissonian type distribution.

These relations are outlined in Figure 2. From Figure 2 and Matsui's equation [12], the balance equation is

$$
\sum_{i=1}^{I_{i}} M I_{i}=n Z
$$

and the balancing principle is

$$
L \sqrt{Z L}<\sum M I_{i}<Z L=W
$$

from (9) and the classic inequality. 


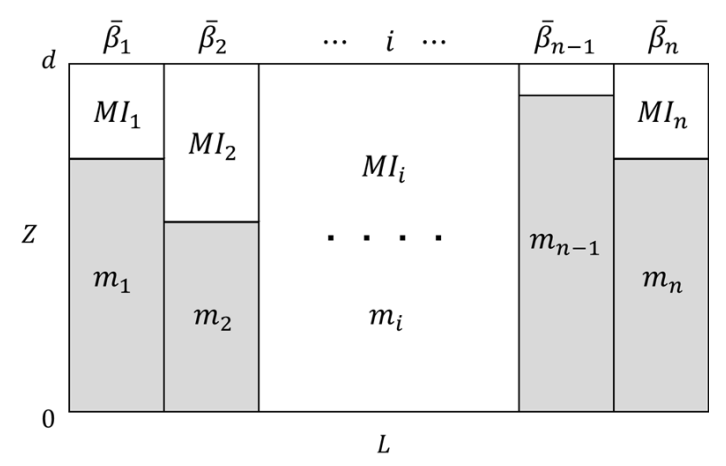

Figure 2. Outline of rebalancing problem and Matsui's equation $(W=Z L)$.

\subsection{Network Flow Principle}

On the lower level, the entity $(i, t)$ is state of the body $i$ and period $t$, and the network flow $(i, t)$ is seen in Figure 3. This network flow would be behaviored under demand speed, $d$, in the body-centered balancing.

Now, the following notations are introduced in each $i(=1,2, \cdots, n)$ and $t(=0,1,2, \cdots)$ from [14]:

$O_{i, t}$ : Order scheduled for body $i$ and period $t$;

$D_{i, t}$ : Expected demand in body $i$ and period $t$;

$I_{i, t}$ : Next inventory at the end of body $i$ and period $t$

$$
\left(=I_{i, t}^{+}-I_{i, t}^{-}\right) \text {. }
$$

where $I_{i, t}^{-}$is the backorder position (quantity).

For each $t$, the balance relation on demand and supply is from Figure 3 and [15] as follows:

$$
O_{i, t}+I_{i-1, t}^{+}+I_{i, t}^{-}=D_{i, t}+I_{i-1, t}^{-}+I_{i, t}^{+}, \quad i=1,2, \cdots, n
$$

From (11), the second balancing principle is obtained as follows:

$$
O_{i, t}=D_{i, t}+\left(I_{i-1, t}^{-}-I_{i, t}^{-}\right)-\left(I_{i-1, t}^{+}-I_{i, t}^{+}\right), \quad i=1,2, \cdots, n, \quad t=1,2, \cdots
$$

where the second and third terms of right hand are corresponded to the coordinating of the moving marginal inventory, $M I_{i, t}$, and end inventory, $I_{i, t}$, at $(i, t)$, respectively.

The equation (11) is similar to that of progressive control in [12]. Thus, our network flow is governed under $d$-balancing by the order quantity, $O_{i, t}$, in (11).

\section{Case of $d$-Balancing}

\subsection{Conveyor System with Stopper}

The usual conveyor systems are the two types of the stations with or without stopper. These systems are treated in [11] by a stochastic approach. This stochastic treatment aids at the minimization of the irregular interruption in delay and idleness at the series type.

A cost approach to the delay and idleness is seen in [11], and this balancing problem is considered by the 2stage method. An example of stopper type is seen in Figure 4, the cycle time is 1.5 minutes, and the number of stations is $n=5$.

The Newsboy method to this case [16] gives the penalty cost function as follows:

$$
E C=\sum_{i=1}^{n} E C_{i}(d), \quad 0<d<\infty
$$

where the right hand consists of the objective of $i$-th station:

$$
E C_{i}(d)=\beta_{1} d+\beta_{2} \int_{0}^{d} f_{i}(d) \mathrm{d} x+\beta_{3} \int_{d}^{\infty} f_{i}(d) \mathrm{d} x
$$




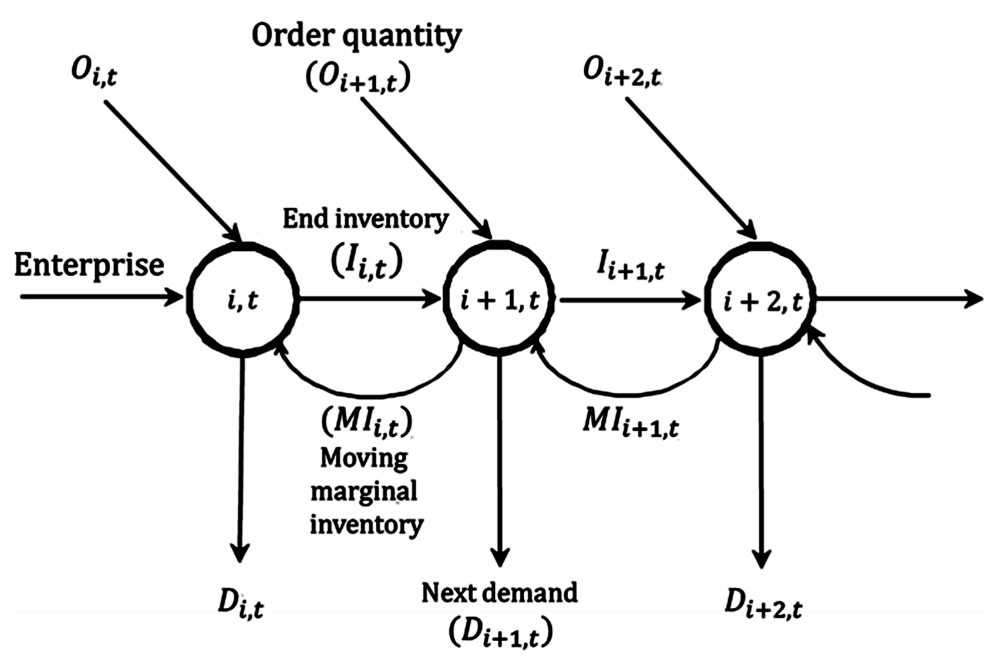

Figure 3. SCM/GDP-economic system: A network flow representation with backorder.

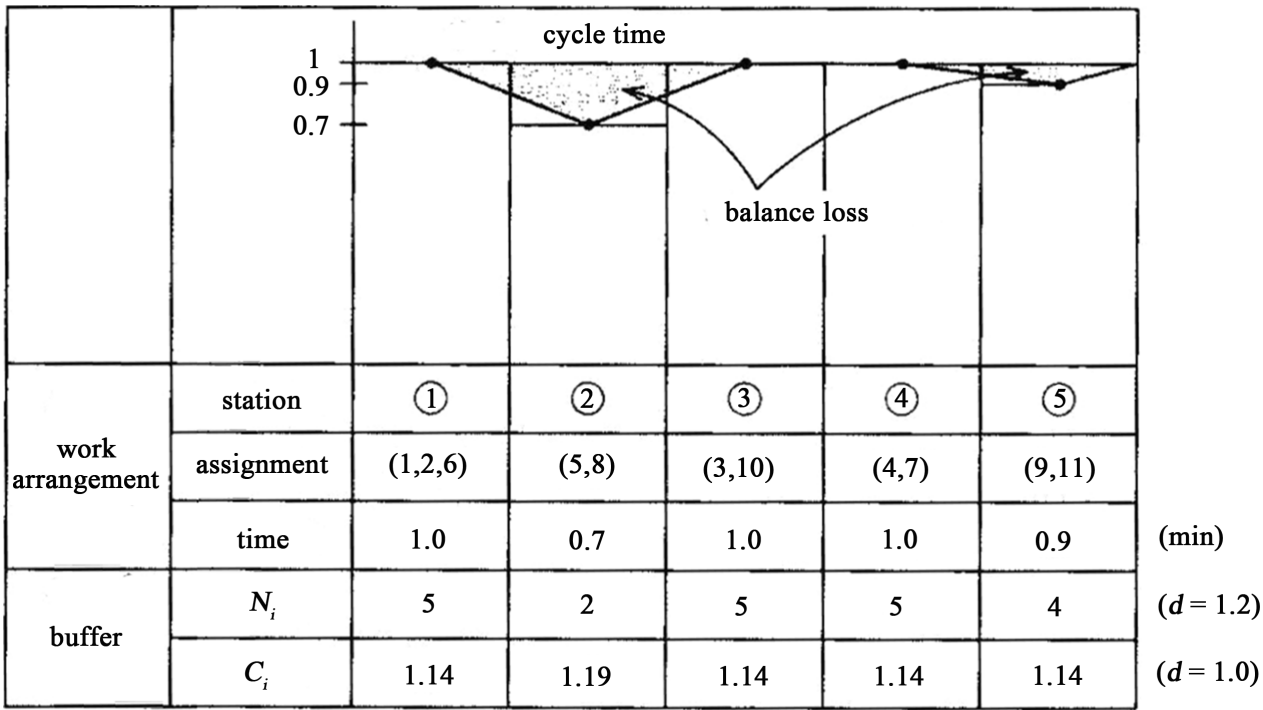

Figure 4. Pitch diagram and buffers: another verification.

in which $f(\cdot)$ is the p.d.f. of work time at the $i$-th station.

Then, the optimal condition is obtained by a differenciation method in the followings:

$$
\sum_{i=1}^{n} f_{i}(d)=n \beta_{1} /\left(\beta_{3}-\beta_{2}\right)
$$

The cycle time, $d$, is determined by the Equation (14), and this equation is here available in replace of (2).

For example, let us $\beta_{1}=5, \beta_{2}=10$ and $\beta_{3}=20$. From (15), the optimal cycle time, $d^{*}$, is given by $d^{*}=1.4$ for the Erlangian with phase $k=5$ in the work time of stations.

\subsection{Two Balancing Views}

Now, let us apply the simulator of SALPS soft [12] to this case. The simulation result is seen in Table 1 , and the optimal cycle time, $d^{\prime}$, is $d^{\prime}=1.3$ with a slight difference. In addition, the total cost would be negligible.

Another verification is considered by Figure 5. From Figure 5, the bottleneck of the system is seen in the stations, $2\left(\bar{\beta}_{2}\right)$ and $5\left(\bar{\beta}_{5}\right)$, in Table 1 . The balancing hypothesis in (3) would be valid. 


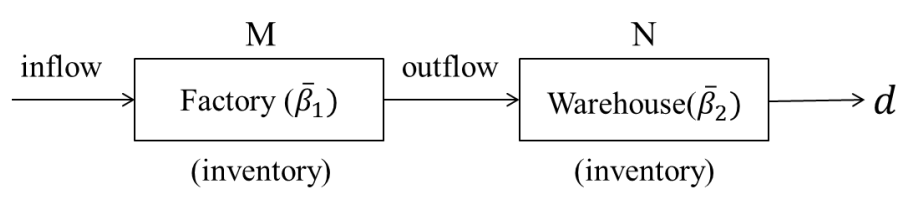

Figure 5. A two-stage supply chain system for balancing.

Table 1. An verification of medium balancing: simulation trial case.

\begin{tabular}{crcccc}
\hline$d$ & total cost & $\bar{\beta}_{1}, \bar{\beta}_{3}, \bar{\beta}_{4}$ & $\bar{\beta}_{2}$ & $\bar{\beta}_{5}$ & $\sum \bar{\beta}_{i}$ \\
\hline 1.0 & 469.5706 & 0.8773 & 0.6608 & 0.8541 & 4.146 \\
1.1 & 91.20302 & 0.7790 & 0.6818 & 0.7973 & 3.816 \\
1.2 & 85.43137 & 0.6692 & 0.6804 & 0.7200 & 3.408 \\
1.3 & 84.78923 (SALPS) & 0.5591 & 0.6604 & 0.6324 & 2.970 \\
1.4 & 84.88829 (optimal) & 0.4561 & 0.6260 & 0.5423 & 2.536 \\
1.5 & 85.45898 & 0.3645 & 0.5813 & 0.4557 & 2.130 \\
1.6 & 86.13179 & 0.2862 & 0.5300 & 0.3761 & 1.765 \\
\hline
\end{tabular}

\section{Case of Network Flow}

\subsection{A Two-Stage Supply Chain}

Next, let us consider the two-stage supply chain (SCM) of a franchise type in Figure 5. This case consists of a series of factory, $M$, and warehouse, $N$, and is seen in Figure 5 [16].

In the case, the outflow is uncontrollable, and the system is only controllable by inflow.

For this case, the balancing problem is the minimization of the total inventory between suppliers. That is,

$$
\text { Net inventory of factory }(M)+\text { Net inventory of warehouse }(N) \rightarrow \min \left\{\bar{\beta}_{i}\right\}
$$

The objective (16) is here available in replace of (2).

\subsection{A SCM Simulation Practice}

For this case, the $\bar{\beta}_{1}-\bar{\beta}_{2}$ balancing table is presented and considered on the network flow balancing. The total inventory in one year is 5176, and is improved much more than the practice (8074).

From Table 2, the medium balancing holds except July, September and April as follows:

$$
\bar{\beta}_{1}, \bar{\beta}_{2}=0.4 \sim 0.5 \text {, except of July, September and April }
$$

It is them noted that any bottleneck phenomena would be doubtful in July, September and April.

This result would show the effectiveness of medium balancing method, and the hypothesis (3) is ascertained.

\section{Conclusions}

This paper summarizes a recent approach (possibility) to the medium (Chameleon's) balancing from conveyor system toward SCM/GDP-economic system. First, the body-balancing problem was briefly outlined. Next, the unified economics treatment to the physical balancing problem was presented.

Finally, an optimal condition of balancing was pointed out and verified at the view of Matsui's equation and Chameleon's criteria. The materials would give a shortcut way to the traditional balancing method, for example, much more than the 2-stage method [11]. By the paper, the concept of balancing is utilized in physics and economics, and is extended to the science of discrete world.

By the further study, the GDP balancing of the country would become probably possible on the base of pro- 
Table 2. A $\bar{\beta}_{1}-\bar{\beta}_{2}$ balancing table.

\begin{tabular}{ccccccc}
\hline month & 6 & 7 & 8 & 9 & 10 & 11 \\
\hline initial inventory & 7000 & 5595 & 7874 & 6632 & 5624 & 8782 \\
$M$-inventory $\left(\overline{\beta_{1}}\right)$ & $58(0.4)$ & $907(0.5)$ & $1010(0.6)$ & $2314(0.7)$ & $1418(0.5)$ & $897(0.5)$ \\
$N$-inventory $\left(\bar{\beta}_{2}\right)$ & $278(0.4)$ & $9(0)$ & $2057(0.5)$ & $1542(0.4)$ & $1607(0.4)$ & $866(0.4)$ \\
outflow & 7723 & 7318 & 14356 & 18485 & 9122 & 15245 \\
inflow & 1059 & 2640 & 9549 & 15710 & 6522 & 8227 \\
inventory & 336 & 916 & 3067 & 3857 & 3025 & 1763 \\
balance & 78,178 & 84,974 & 54,502 & 47241 & 58,050 & 61,907 \\
stock out & 0 & 0 & 0 & 0 & 0 & 0 \\
month & 12 & 1 & 2 & 3 & 4 & 5 \\
initial inventory & 6104 & 10636 & 5856 & 13343 & 12626 & 7510 \\
$M$-inventory $\left(\overline{\beta_{1}}\right)$ & $1851(0.5)$ & $254(0.5)$ & $2577(0.5)$ & $91(0.3)$ & $2307(0.1)$ & $2837(0.5)$ \\
$\begin{array}{c}N \text {-inventory }\left(\overline{\beta_{2}}\right) \\
\text { outflow }\end{array}$ & $1490(0.4)$ & $1233(0.4)$ & $883(0.4)$ & $96(0.4)$ & $1386(0.4)$ & $2207(0.5)$ \\
inflow & 11,201 & 19,609 & 13,748 & 23,422 & 13,055 & 9904 \\
inventory & 8438 & 10460 & 11,352 & 10,266 & 4122 & 6911 \\
balance & 3341 & 1487 & 3460 & 187 & 3693 & 4517 \\
stock out & 23,779 & 75,988 & 35,552 & 126,559 & 83,958 & 29,870 \\
\hline
\end{tabular}

gressive and autonomous control of marginal profit/value in GDP networks. This foundation may be derived by changing from the invisible hand to visibility of demand-to-supply speed.

\section{References}

[1] Weeks, J.K. (1979) Optimizing Planned Lead Time and Delivery Dates. 21st Annual Conference Proceedings, APICS, USA, 1979, 177-188.

[2] Wild, R. (1972) Mass-Production Management, the Design and Operation of Production Flow-Line Systems. Wily, London.

[3] Stamp, D. (1995) The Invisible Assembly Line-Boosting White-Collar Productivity in the New Economy. AMACOM, New York.

[4] Ohno, T. (1988) Toyota Production System: Beyond Large-Scale Productivity Press.

[5] Smith, A. (1776) The Wealth of Nations, Encyclopedia Britannica. 1952 Edition.

[6] Keynes, J.M. (1936) The General Theory of Employment, Interest and Money. The Macmillan Press, London, 1973 Edition.

[7] Matsui, M. (2010) Division of Work, Stochastic (Re-) Balancing and Demand Speed: From Assembly Line toward Demand Chain. Journal of Japan Industrial Management Association (JIMA), 60, 324-330.

[8] Matsui, M. (2013) Modern God-Like Hand: Cloud Balancing Issues on Global SCM Networks and Economics. Euro-Asia Economic Forum (EAEF 2013), Xi'an, 26-28 September 2013, 285.

[9] Matsui, M. (2012) Economic Station-Centered Network and Invisible Collaboration: A Cyclic vs. Semi-Cyclic View. Theoretical Economics Letters, 2, 344-349. http://dx.doi.org/10.4236/tel.2012.23063

[10] Matsui, M. (2012) Economic Demand-Balancing Problem of Multi-Center. In: Tavdize, A., Ed., Progress in Economics Research, Vol. 25, NOVA, New York, 227-235.

[11] Matsui, M. (2008) Manufacturing and Service Enterprise with Risks: A Stochastic Management Approach. Springer, 
New York.

[12] Matsui, M. (2014) Manufacturing and Service Enterprise with Risks II: The Physics and Economics of Management. Springer, Tokyo.

[13] Smith, A. (1759) The Theory of Moral Sentiments. 1970 Edition, Oxford University Press, London.

[14] Matsui, M. (2011) Conveyor-Like Network and Balancing. In: Savarese, A.B., Ed., Manufacturing Engineering, NOVA, New York, 65-87.

[15] Johnson, L.A. and Montgomery, D.C. (1974) Operations Research in Production Planning, Scheduling and Inventory Control. Wiley, New York.

[16] Matsui, M. (2014) Medium (Chameleon's) Balancing: From Conveyor System toward Supply Chain, Reprints of Japan Industrial Management Association. Spring, Chiba, 16-21. (In Japanese) 